\title{
The Relationship between Quality of Working Life and Job Involvement of Employees in Chamran Hospital
}

\author{
Zeinab Sirous Jahedi \\ Student of Ph.D, Department of Public Psychology, college of human science, \\ Bushehr Branch, Islamic Azad University, Bushehr, Iran
}

Ali Pouladi Reyshahri

Ph.D of Public Psychology, Member of faculty in Payamenoor university of Bushehr Branch

Doi:10.5296/ jsr.v6i2.8980 URL: http://dx.doi.org/10.5296/ jsr.v6i2.8980

\begin{abstract}
The present study was conducted with the aim of representing the relationship between quality of work and work attachment of employees in Chamran hospital in Saveh in 2015. The research was practical in terms of objective and descriptive-correlational in terms of data collection. The population consisted of 300 employees of Chamran hospital in Saveh among whom 169 individuals were chosen as a sample size using simple random sampling method and Morgan table. Data collection was carried out through standard questionnaire. Analysis of the obtained data was performed using SPSS 21 software in two parts of descriptive and inferential (Regression and Pearson Correlation). The results indicated that there is a significant and positive relationship between quality of working life and its dimensions including fair payment, safe and healthy working environment, providing opportunities for continuous growth and security, legalism, social solidarity and cohesion, and development of human capabilities with job involvement of employees in Chamran hospital in Saveh.
\end{abstract}

Keywords: Quality of work life, job involvement, fair payment, continuous security 


\section{Introduction}

Hospitals, which are deemed as one of the most important executive sectors in the field of health and hygiene, are service organizations that play an important role in maintaining and developing society health. According to the population growth and low number of hospitals and lack of facilities, and need for greater efficiency of the existing facilities have resulted in more attention and emphasis on important factors such as human resources working in these organizations. On other words, organizations must not only seek to attract and recruit excellent talent but also should inspire the employees and empower them to employ their maximum ability (Bakker et al., 2011). Work attachment refers to the extent one replicate his job, involve himself in the job actively and respect his performance as an important factor in order to valorize himself (Robins \& Carter; cited in Mehrabizadeh Honarmand \& Talebzadeh, 2001). According to them, job involvement refers to as a positive mental state associated with the occupation which is defined as energy, dedication and job attraction. Employees involved in their work have a tremendous amount of energy and enough enthusiasm to perform their job duties. Emergence of job involvement among the employees of an organization results in positive consequences for the organization including organizational citizenship behavior, job satisfaction, safety performance, and not wanting to leave the organization, consequently, identify factors influencing elevation of job involvement is significant in the meantime (Keshtkaran et al., 2012). Positive consequences of job involvement in organizations makes the necessity of considering the issue clear, there by employees who are interested in the job make a better relationship with what they do and respond better to demands of their job. They hope their work more and are less susceptible to mental or physical fatigue (Mir Mohammadi et al., 2012). Moreover, relevant researches indicated that job involvement is related to performance safety and is a hedge against the effects of job stress on the person (Neveu, 2007).

Therefore, according to the significant influence of job involvement of employees which leads to enhancement of job satisfaction, increase of organizational commitment and reduction of job changes (Bakker et al., 2011; Hassan \& Ahmed, 2011), organizations should strive to improve their employees' standard of living in order to walk towards improvement of the organization using such an approach. Moreover, adopting this approach (quality of working life) leads to the alignment of employee with organization (Richardson et al., 2000). The concept of quality of working life in the contemporary management has become a significant social issues around the world, while it was focused on non-working life in the past decades. Proponents of the theory of quality of working life are in search of a new system to help employees in order to establish a balance between working life and personal life (Mir Kamali \& Narenji Sani, 2008). Quality of working life is a multidimensional issue including welfare and health facilities, job security, job design, job security, career development and progression, training, improvement, etc. On other words, focus of the concept of quality of working life could be found within the organization. Many investigations have declared that quality of working life has an important impact on behavioral reactions of employees such as job satisfaction, job efforts, job performance, intention to leave the organization and organizational relocation (Sirgy et al., 2001). It has been tried to elevate employees' productivity through promotion of their intrinsic motivation 
in many of programs dedicated to quality of working life. Research findings demonstrated that implementation of such programs results in reducing the extent of employees' complaints, reducing the rate of absenteeism, reducing the extent of employment of disciplinary regulations, increasing positive attitudes of employees and increasing their participation in the programs of recommendation system (Dahl \& Olsen, 2009).

Considering quality of working life has always brought a great achievement for organizations in terms of efficiency. Quality of working life refers to the level or degree of satisfaction, motivation, participation, commitment and accountability of employees in the workplace and it is of the most important factors which shows that to what extent one is able to satisfy his personal needs at work and in the organization such as when he is at home or in society. Whatever the demands and needs of a person are met, he is more likely to have more job involvement and to be more satisfied with his supervisors and colleagues (Bazzaz Jazayeri, 2006).

As mentioned before, the focus of the concept of quality of working life could be found within the organization and this could have a great impact on performance of the organization. Organizations try to maintain and grow their employees as well as improve organizational performance through promoting the level of quality of working life of their employees. According to Gonzalez \& Grazzo (2006), employees who have healthy work environment walk towards more efficiency and better working environment by applying all their energies. In addition, they expressed that employees with high levels of job involvement are more satisfied with their job and more successful. Moreover, leaving the job and absenteeism rates are less in comparison to workers with low job involvement (Gonzalez \& Grazzo, 2006). Job involvement helps individuals with organizational effectiveness, employee morale and positive perceptions of work (Rogelberg \& Reiter-Palmon, 2007).

What is particularly notable in the relationship between quality of working life and job involvement is the role of hospitals as a social institution in the field of hygiene, health and treatment of citizens. Quality of working life of employees of hospitals should be precisely studied due to their job difficulties and specific job characteristics of these health centers. Accordingly, lack of attention to the situation of this category of service organizations leads to devastating effects on the quality of service and physical and mental health of employees in such organizations in the long run. Thus, considering the importance of these concepts (quality of working life and job involvement), conducting a study in this regard seems to be mandatory.

Therefore, since employees in a hospital are connected with different strata of society in different ways, it is expected that development of their competencies and providing an environment that makes them more committed and attached to their jobs have a great impact on the quality of services they offer. Hence the present research is going to answer to the following question. Is there any relationship between quality of working life and job involvement of employees in hospitals in Saveh?

Based on this, the following research model and hypotheses are presented. 
Main hypothesis

1. There is a relationship between quality of working life and job involvement of employees in hospitals.

\section{Subsidiary hypotheses}

1. There is a relationship between fair payment and job involvement of employees in hospitals.

2. There is a relationship between safe and healthy working environment and job involvement of employees in hospitals.

3. There is a relationship between providing opportunities for continuous growth and security and job involvement of employees in hospitals.

4. There is a relationship between legalism and job involvement of employees in hospitals.

5. There is a relationship between social dependency and job involvement of employees in hospitals.

6. There is a relationship between overall atmosphere of life and job involvement of employees in hospitals.

7. There is a relationship between social solidarity and cohesion and job involvement of employees in hospitals.

8. There is a relationship between development of human capabilities and job involvement of employees in hospitals.

The conceptual model of the research is as follows. 


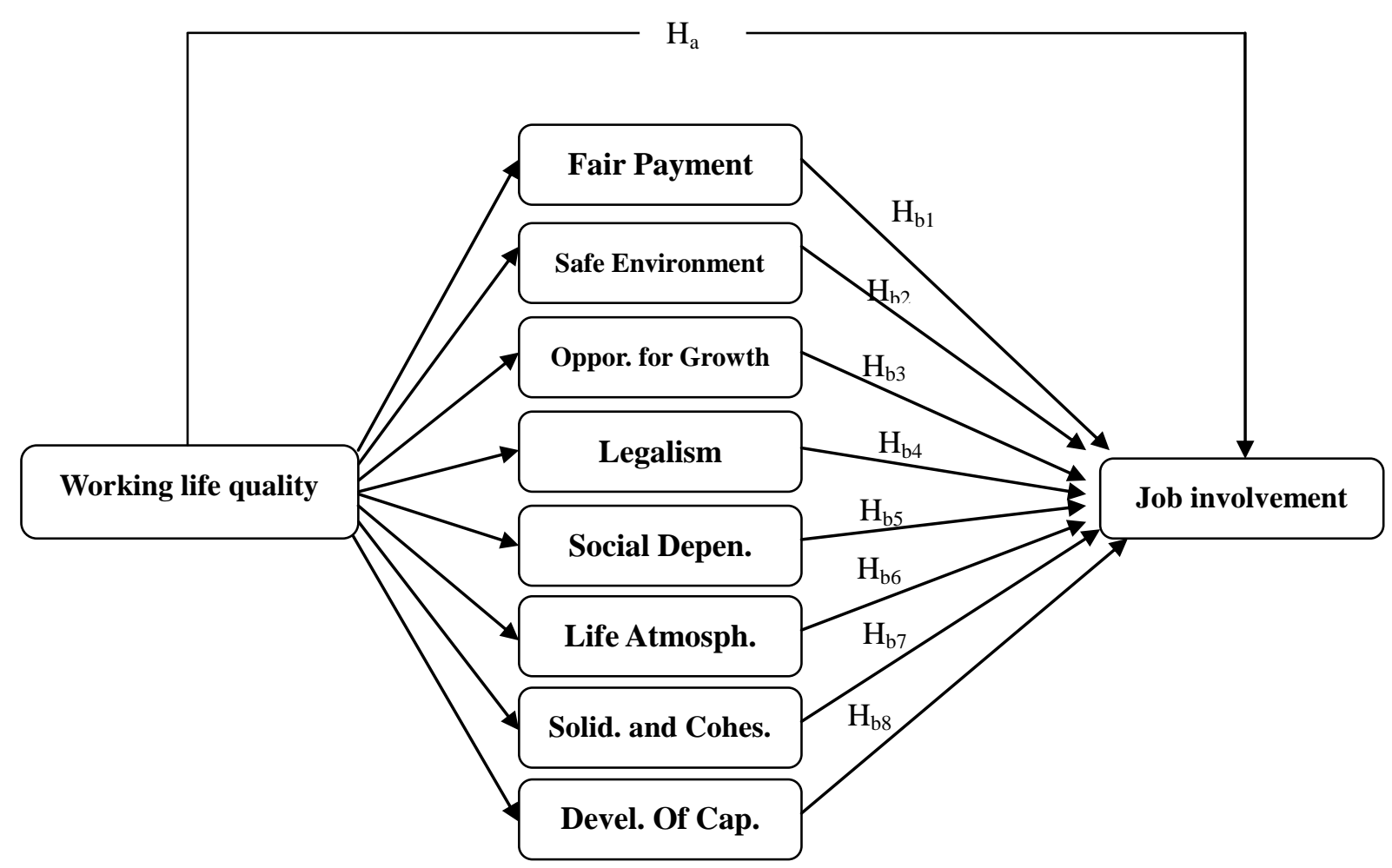

Figure 1: Conceptual model of the research

\section{Methodology}

The research was practical in terms of objective and descriptive-correlational in terms of data collection. The population consisted of 300 employees of Chamran hospital in Saveh among whom 169 individuals were chosen as a sample size using simple random sampling method and Morgan table.

Data collection was carried out through standard questionnaire. Specialized questions in this section includes questions related to quality of working life and job involvement so that 32 questions are dedicated to assessment of quality of working life, which all the questions follow 5-point Likert scale (from "very low" to "very high"). The next section is related to the measurement of job involvement with 20 questions. Similarly, the questions follows 5-point Likert scale (from "strongly disagree" to "strongly disagree").

The questions related to "quality of working life" and "job involvement" were obtained from Richard Walton standard questionnaire of quality of working life (1973) and Kanungo standard questionnaire (1982), respectively. The following table refers to the variables and corresponding questions.

Table 1: distribution of items and investigation of reliability for each of the research variables 


\begin{tabular}{|c|c|c|c|}
\hline Dimension & Component & $\begin{array}{l}\text { No. of } \\
\text { item }\end{array}$ & $\begin{array}{l}\text { Reliability } \\
\text { coefficient }\end{array}$ \\
\hline \multirow{8}{*}{$\begin{array}{l}\text { Quality of } \\
\text { working life }\end{array}$} & Fair payment & $1-5$ & 0.604 \\
\hline & Safe and healthy working environment & $6-8$ & 0.796 \\
\hline & $\begin{array}{l}\text { Providing opportunities for continuous growth } \\
\text { and security }\end{array}$ & $9-11$ & 0.734 \\
\hline & Legalism & $12-20$ & 0.831 \\
\hline & Social dependency in working life & $21-22$ & 0.739 \\
\hline & Overall atmosphere of life & $23-25$ & 0.711 \\
\hline & Social solidarity and cohesion & $26-27$ & 0.661 \\
\hline & Development of human capabilities & $28-32$ & 0.741 \\
\hline \multirow{2}{*}{$\begin{array}{l}\text { Job } \\
\text { involvement }\end{array}$} & Commitment to organization & $33-39$ & 0.884 \\
\hline & Job satisfaction & $40-52$ & 0.799 \\
\hline
\end{tabular}

Face and content validity methods were used to investigate the research validity. In this regard, the questionnaire was given to specialists and scholars in order to confirm its face validity. The results of validity investigation indicated that the obtained Cronbach's alpha for the whole questionnaire (52 questions) was equal to 0.94. In addition, the reliability coefficients calculated for the two main constructs of the research were more than 0.7 .

Data analysis was carried out in two parts of descriptive and inferential. In the first part, demographic information and descriptive statistics of the variables were presented. Afterwards, correlation and regression tests in SPSS software were utilized to investigate the research hypotheses.

\section{Findings}

\subsection{Descriptive findings}

The research findings in descriptive statistics section (characteristics of participants) indicated that most of the participants consisted of men. Most of the sample group are employees who have a Bachelor's degree. Moreover, Most of the subjects' age range is between 28 to 38 years and most of the employees had 9-14 work experience.

Results of hypotheses testing 
Prior to hypotheses testing, normal distribution of data was evaluated using the Kolmogorov-Smirnov test. The results indicated that the distribution is normal for all the dimensions and components because the significance level of the variables were more than 0.05. As it was noted in the present research, inferential statistic is dedicated to correlation and regression tests using SPSS software which the results related to the main and subsidiary are listed in the following table.

Research hypotheses: there is a relationship between quality of working life and its dimensions (fair payment, safe and healthy working environment, providing opportunities for continuous growth and security, legalism, social solidarity and cohesion, and development of human capabilities) and job involvement of employees in hospitals in Saveh.

The results relate to the relationship between the two main dimensions and components of quality of working life is mentioned in table 2 .

Table 2: result of correlation test between quality of working life and its dimension and job involvement

\begin{tabular}{|l|l|l|l|}
\hline Correlation relationship & Sig. level & $\begin{array}{l}\text { Pearson } \\
\text { correlation } \\
\text { coefficient }\end{array}$ & Result \\
\hline $\begin{array}{l}\text { Quality of working life and job } \\
\text { involvement }\end{array}$ & 0.001 & 0.732 & Approved \\
\hline Fair payment and job involvement & 0.001 & 0.312 & Approved \\
\hline $\begin{array}{l}\text { Safe and healthy working environment } \\
\text { and job involvement }\end{array}$ & 0.001 & 0.457 & Approved \\
\hline $\begin{array}{l}\text { Providing opportunities for growth and } \\
\text { job involvement }\end{array}$ & 0.001 & 0.502 & Approved \\
\hline Legalism and job involvement & 0.001 & 0.464 & Approved \\
\hline Social dependency and job involvement & 0.001 & 0.381 & Approved \\
\hline $\begin{array}{l}\text { Overall atmosphere of life and job } \\
\text { involvement }\end{array}$ & 0.001 & 0.336 & Approved \\
\hline job involvement & 0.001 & 0.782 & Approved \\
\hline Social solidarity and job involvement & 0.811 & Approved \\
\hline
\end{tabular}


Since the significance level were less than 0.01 in all the hypotheses, it can be declared that there is a positive and significant relationship between quality of working life and its components and job involvement. Moreover, the positive sign for the correlation coefficients in the above table indicates that there is a direct relationship between the variables. This means increase or decrease of a variable leads to increase or decrease of the other one.

\subsection{Regression testing}

After performing correlation testing, the impact of variables on each other was investigated through simple and multiple regression tests. It should be mentioned that researcher can use linear regression only when its hypotheses are evaluated, hence independency of errors (difference between real values and values predicted by regression equation) in the present study was investigated using Durbin-Watson test. Moreover, the normality of errors (distribution of errors must be normal with average equal to zero) was investigated. Finally, all the hypotheses were approved.

The following table refers to the results of regression testing. According to the table, the results related to the impact of variables on each other are stronger than the results of the correlation test. This means variables have strong impact (unidirectional) on each other instead of a bidirectional relationship. In fact, since the dependent and independent variables are specified, the result of the impact of variables is stronger. Accordingly, the regression equation is mentioned in the following.

$Y=0.594 X_{1}+0.654 X_{1}+0.713 X_{1}+0.71 X_{1}+0.699 X_{1}+0.63 X_{1}+0.754 X_{1}+0.69 X_{1}$

Table 3: result of regression test

\begin{tabular}{|l|l|l|l|l|l|}
\hline Variables entered the model & model & t & $\begin{array}{l}\text { Sig. } \\
\text { level }\end{array}$ & B & Beta \\
\hline Quality of working life & y-intercept & 12.21 & 0.001 & 0.673 & 0.795 \\
\hline Fair payment & Variable Coef. & 13.036 & 0.001 & 0.540 & 0.729 \\
\hline $\begin{array}{l}\text { Safe } \\
\text { environment }\end{array}$ & Variable Coef. & 8.927 & 0.001 & 0.561 & 0.594 \\
\hline Providing opportunities for growth & Variable Coef. & 15.839 & 0.001 & 0.763 & 0.713 \\
\hline Legalism & Variable Coef. & 14.795 & 0.001 & 0.550 & 0.654 \\
\hline Social dependency & Variable Coef. & 15.339 & 0.001 & 0.893 & 0.710 \\
\hline
\end{tabular}




\begin{tabular}{|l|l|l|l|l|l|}
\hline Overall atmosphere of life & Variable Coef. & 11.510 & 0.001 & 0.488 & 0.630 \\
\hline Social solidarity & Variable Coef. & 16.224 & 0.001 & 0.503 & 0.754 \\
\hline Development of human capabilities & Variable Coef. & 12.203 & 0.001 & 0.752 & 0.690 \\
\hline
\end{tabular}

According to table 3 , since the significance level is less than the amount of error $(0.01)$ in the tests including simple regression (the first row) and multiple regression (the second row to the end), the null hypothesis is rejected at $99 \%$ confidence level and the first hypotheses are approved. On other words, quality of working life and its dimensions have significant impact on job involvement. The positive sign indicates the direct impact between the variables. This means improvement in quality of working life leads to elevation of job involvement.

\section{Conclusion}

The present research was conducted with the purpose of representing the relationship between quality of work and work attachment of employees in Chamran hospital in Saveh in 2015. After analysis of the data obtained from SPSS software, it was concluded that there is a positive and significant relationship between quality of working life and job involvement. Moreover, it was depicted that the higher the quality of working life of employees, the higher their job involvement. Consequently, effectiveness and efficiency of the organization's activities increases.

As it was mentioned before, programs dedicated to quality of working life including any improvement in organizational culture are as an advocate for the growth and development of employees in the organization. Hence the value system of quality of working life considers "investment in people" as the most important variable in strategic management. On other words, meeting employees' needs leads to effectiveness and efficiency of organization and increase their employees' commitment to the job and organization.

Findings indicated that there is a relatively good relationship between quality of working life and job involvement in the studied organization and any actions and activities to improve the quality of working life of individuals not only leads to increase in job satisfaction, productivity and morale but also it is accompanied by an increase in job involvement. On other words, elevation of quality of working life makes the individuals more committed and loyal to his work. It should be noted that positive aspects of job involvement was meant here.

Generally, the results of the research was in line with the findings of Caillier (2012), Hong et al. (2012), Fakhrpour et al. (2012) and Imami \& Baharestani (2012) who declared that quality of working life is an important component for the interests of employees and improvement of their job satisfaction and performance. Totally, it can be concluded by deducting from the result of the hypotheses that human resources are the most important unit for organizations and organizations could expect improvement in job involvement and consequently, effectiveness from employees with regard to elevation of their quality of working life. The subsidiary hypotheses are explained in the following. 
In the case of fair payment to employees based on their work and also motivational payments to employees which could have positive impact on their perception of workplace, elevation of job involvement could be seen within the organization. In addition, adequate payment and fringe benefits result in more satisfaction with work.

When individuals do not feel safe in their job and continuously concerns for loss of jobs, this has negative impact on working atmosphere and leads to inappropriate implementation of tasks. Furthermore, this makes people not do their job well, reduces job satisfaction, reduce their job involvement, makes individuals' attitudes towards the organization unfavorable and consequently, their productivity decreases. Organization can motivate employees through creating safe working conditions physically and logical working hours for staff, thereby effectiveness and efficiency of the organization and job involvement of employees increases. Mental tranquility in the workplace, physical health of the workplace, health care for the family of employees, health and medical services in the workplace and health and safety laws and regulations lead to improvement of individuals' performance within the organization.

If an organization provide a condition in which employees can promote based on their performance, this could lead to performance improvement and it has positive effect on their job involvement.

Legalism refers to "creating conditions for employees' freedom of speech without fear of retaliation and dominance of rule of law over human". If legal criteria rule the organization, then treatment based on individual interest decreases, one cannot make decisions based on personal opinions, tasks are institutionalized and individuals speak without fear. Therefore, such an atmosphere in the organization makes the employees more committed to their workplace and leads to more job involvement.

Social dependency refers to organization's social responsibility, vivid perception of employees of goals and objectives. This means that elevation of social dependency of working life leads to increase in productivity. Based on this, it seems necessary for organizations to provide proper cultural infrastructures in order to institutionalize needs for attention to social responsibility. More social dependency of employees (means high level of confidence in the society, especially workplace) results in more job involvement and makes the employees feel as a part of the organization.

The indices of the component of overall atmosphere of working life are in line with balance between personal life and social life, performance of other social roles, continuing education, etc. This component refers to establishment of a balance between working life and other life responsibilities of employees. According to Walton, creating a direct correlation between work and overall atmosphere of life through establishing the concept of balance between workers' time at work and his time for his family could lead to a balance between the person's work and his life to a large extent.

Social integration says that when there is social solidarity and cohesion in an organization, in addition to the employees' demands and needs, the manager can understand the distinctions and differences between them and tries to choose an integrated approach as policy, thereby 
this elevates the employees' accountability and satisfaction. Indices of the component are non-discrimination between employees, trust between employees and support of colleagues. According to researchers, lack of prejudice towards race and gender and mobility towards the up side of organizational hierarchy, establishment of the sense of sociability in organizations, individuals' freedom to express ideas and feelings and creation of an atmosphere in which the feeling of belonging to the organization and the organization's needs to them are strengthened are of factors lead to organizational integrity.

Individual capabilities refers to availability of opportunities such as using independence and self-control in work, taking advantage of various skills and having access to appropriate information at work. Human beings nowadays have new expectations regarding knowledge gained as a result of global changes. In fact, today's human has many differences from the previous version. Moreover, speed of entrance of information and knowledge and volume, quality and breadth of its scope are such broad, fast and large that dominating today's world is also astonishing for great brains. Humans do not like to be as an anonymous piece but they want to see the influence of what they perform. Monotonous and boring work, especially when it does not result in a perfect product, leads the personnel to exhaustion. Such circumstances is not compatible with the nature of human and bring about job dissatisfaction. On the contrary, it can be expressed that managers make their employees feel that their individual capabilities and abilities could be developed when they pay special attention to the requirements of their employees, provide groundwork for their progress and motivate them. Consequently, this enhances employees' job involvement. According to what have been mentioned, the following recommendations are proposed:

- Safety and hygiene standards should be provided for all the existing professions with the participation of health professionals and protection and safety authorities, managers and administrators and representative of employees.

- To create an integrated system in order to select employees (test)

- To hold training and education courses in order to familiarize employees with laws and regulations.

- To elevate employees' educational level through internal tests or part-time university classes.

- To create academic facilities for newly added employees.

\section{References}

1. Bakker, A. A., Albrecht, S. L., \& Leiter, M. P. (2011). Key question regarding work engagement. European journal of work and organizational psychology, 20(1), 4-28.

2. Bazzaz Jazayeri, S.A. (2006). Development of a working life quality model, Ph.D. Dissertation, Shahid Beheshti University.

3. Caillier, J. G. (2012). Satisfaction With Work-Life Benefits and Organizational 


\section{Macrothink}

Journal of Sociological Research

ISSN 1948-5468

2015, Vol. 6, No. 2

Commitment/Job Involvement: Is There a Connection? Review of Public Personnel Administration.

4. Dahl, S. Å., N.T., \& Olsen, K. M. (2009). Quality of work: concept and measurement. REC-WP Working Papers on the Reconciliation of Work and Welfare in Europe Conference.

5. Fakhrpour, R., Yavari, Y., Amirtash, A.M. \& Tondnevis, F. (2012). The relationship between working life quality and organizational commitment of faculty members and departments of physical education in universities, Sport Management, Issue 13, pp. 153-168.

6. Gonzalez, J and Grazzo, T. (2006). "Structural relationships between organizational service orientation, contact employee job satisfaction and citizenship behavior". International Journal of Service Industry Management, 17(1), 23-50.

7. Hassan, A., and Ahmed, F. (2011). Authentic leadership, trust and work engagement. International journal of human and social science, 6 (3).

8. Hong, K. S., Tan, K. W., \& Bujang, S. (2012). Relationships between work life quality of teachers with work commitment, stress and satisfaction: a study in Kuching, Sarawak, Malaysia. Journal Technology, 52(1), 1-15.

9. Imami, M. \& Baharestani, M. (2012). Study of the relationship between working life quality and professional commitment of employees (case study: Iranian National Oil Refining and Distribution Company, Kermanshah). The first international conference in national management, innovation and manufacturing, Qom: Payam Nour University of Qom).

10. Kanungo, R. N. (1982). Measurement of job and work involvement. Journal of applied psychology, 67(3), 341.

11. Keshtkaran, A., Kavousi, Z., Gholipour, A., Sohrabizadeh, S. \& Sharafi, Z. (2013). Job involvement and factors affecting it among nurses of training hospitals in Shiraz University of Medical Sciences, Peyavard Salamat, Vol. 6, Issue 2, pp. 147-156.

12. Mehrabizadeh Honarmand, M. \& Talebzadeh, A. (2001). Study of the relationship of ambiguity and role conflict with happiness and job involvement, Journal of Psychology, 5(17), pp. 44-55.

13. Mir Kamali, M. \& Narenji Sani, F. (2008). Study of the relationship between working life quality and job sarisfaction among faculty members of Tehran and Sharif University of Technology, Journal of Research and Planning in Higher Education, Issue. 48, pp. 71-103.

14. Mir Mohammadi, S.M., Rahimian, M. \& Jalali Khanabadi, T. (2012). Authentic Leadership and Job Involvement: trust as a mediating variable, Perspective on Public Management, Issue 12, pp. 15-34. 
15. Neveu JP. (2007). Jailed resources: Conservation of resources theory as applied to burnout among prison guards. Journal of Organizational Behavior. 28, 21-42.

16. Richardson, H., Vandenberg, R. \& Wilkerson, J. (2000). Using Systems of Practices to Gain Top Performance, Loma, (Reprinted From RESOURCE).

17. Rogelberg, S. G., \& Reiter-Palmon, R. (2007). The Encyclopedia of Industrial and Organizational Psychology. Sage Publication.

18. Sirgy, M. J., Efraty, D., Siegel, P., \& Lee, D. J. (2001). A new measure of quality of work life (QWL) based on need satisfaction and spillover theories. Social indicators research, 55(3), 241-302.

19. Walton, R. E. (1973). "Quality of work life: what is it?" Sloan Management Review, fall. 